\title{
Gravity with Gravitas: A Solution to the Border Puzzle*
}

\author{
James E. Anderson \\ Eric van Wincoop \\ Boston College and NBER Federal Reserve Bank of New York
}

December 2000

${ }^{*}$ We would like to thank Carolyn Evans, Jim Harrigan, John Helliwell, Russel Hillberry, David Hummels, Andy Rose, and Kei-Mu Yi for discussions and helpful comments on earlier drafts. We also like to thank seminar participants at Boston College, Brandeis University, Tilburg University, Vanderbilt University, University of Virginia, and the NBER ITI Fall meeting for helpful comments. The views expressed in the paper are those of the authors and do not necessarily reflect the position of the Federal Reserve Bank of New York or the Federal Reserve System. 


\begin{abstract}
The gravity model has been widely used to infer substantial trade flow effects of institutions such as customs unions and exchange rate mechanisms. McCallum [1995] found that the US-Canada border led to trade between provinces that is a factor $22(2,200 \%)$ times trade between states and provinces, a spectacular puzzle in light of the low formal barriers on this border. We show that the gravity model usually estimated does not correspond to the theory behind it. We solve the "border puzzle" by applying the theory seriously. We find that national borders reduce trade between the US and Canada by about 44\%, while reducing trade among other industrialized countries by about 30\%. McCallum's spectacular headline number is the result of a combination of omitted variables bias and the small size of the Canadian economy. Within-Canada trade rises by a factor 6 due to the border. In contrast, within-US trade rises $25 \%$.
\end{abstract}




\section{Introduction}

The gravity model has been widely used to infer substantial trade flow effects of institutions such as customs unions, exchange rate mechanisms, ethnic ties, linguistic identity and international borders. The most celebrated inference is McCallum's [1995] finding that the US-Canadian border led to 1988 trade between Canadian provinces that is a factor $22(2,200 \%)$ times trade between US states and Canadian provinces. Obstfeld and Rogoff [2000] pose it as one of their six puzzles of open economy macro-economics. Helliwell and McCallum [1995] document its violation of economists' prior beliefs. Grossman [1998] says it is an unexpected result, even more surprising than Trefler's [1995] 'mystery of the missing trade'. In consequence of this and because of the importance of trade costs for economic geography and macroeconomics, a rapidly growing literature is aimed at measuring and understanding trade border effects. ${ }^{1}$ So far none of the subsequent research has explained McCallum's finding. We solve the border puzzle in this paper by applying the theory of the gravity equation seriously.

While gravity equations used in empirical applications are known for their strong fit to the data, the estimated equations do not correspond to those derived theoretically. The theory, first developed by Anderson [1979], tells us that after controlling for size, trade between two regions is decreasing in their bilateral trade barrier relative to the average barrier of the two regions to trade with all their partners. Intuitively, the more resistant to trade with all others a region is, the more it is pushed to trade with a given bilateral partner. We define a theoretically appropriate average barrier below and call it multilateral resistance. McCallum did not include multilateral resistance variables in his analysis. Most of the subsequent literature does include a form of multilateral resistance in the form of an atheoretic remoteness variable related to distance from all bilateral partners. But the remoteness index does not include national border barriers, even though these are the focus of this literature, and its functional form is at odds with the theory. ${ }^{2}$

\footnotetext{
${ }^{1}$ See Anderson and Smith [1999a,b], Chen [2000], Head and Ries [1999], Evans [2000a,b], Helliwell [1996,1997,1998], Helliwell and McCallum [1995], Helliwell and Verdier [2000], Hillberry [1998,1999], Hummels [1999], Messinger [1993], Wei [1996], and Wolf [2000].

${ }^{2}$ Bergstrand [1985, 1989] acknowledges the multilateral resistance term and deals with its time series implications, but is unable to deal with the cross section aspects which are crucial for proper treatment of bilateral trade barriers. Anderson and Marcouiller [1999] approximate the
} 
We will show that basing the empirics on the theoretically grounded gravity equation not only affects estimates of the impact of national borders on trade, but also provides a much more useful interpretation of the findings.

The primary concern of policy makers and macroeconomic analysts is the impact of borders on international trade. McCallum's regression model (and the subsequent literature following him) cannot validly be used to infer such border effects. In contrast, our theoretically grounded approach can be used to compute the impact of borders both on intranational trade (within a country) and international trade. Applying our approach to 1993 data, we find that borders reduce trade between the US and Canada by 44\%, while reducing trade among other industrialized countries by $29 \%$. While not negligible, we consider these to be plausibly moderate impacts of borders on international trade.

Two factors contribute to making McCallum's ceteris paribus ratio of interprovincial to province-state trade so large. First, his estimate is based on a regression with omitted variables, the multilateral resistance terms. Estimating McCallum's regression for 1993 data we find a ratio of 16.4, while a consistent estimate based on the theoretical gravity equation implies a ratio of 10.7. Second, the magnitude of both ratios largely reflects the small size of the Canadian economy. If we estimate McCallum's regression with US data, we find that trade between states is only a factor 1.5 times trade between states and provinces. The intuition is simple in the context of the model. Even a moderate barrier between Canada and the rest of the world leads to high multilateral resistance for the provinces because it affects trade barriers between a province and almost all of its potential trading partners. This significantly raises interprovincial trade, by a factor 6 based on our estimated model. In contrast, the multilateral resistance of US states is much less affected by a border barrier since it does not affect the barrier between a state and the rest of the large US economy. Therefore trade between the states is not much increased by border barriers.

To a large extent the contribution of this paper is methodological. Our specification can be applied in many different contexts in which various aspects of

price index term for importers in cross section variation, but avoid the exporters price index by estimating a relative import demand form. In contrast, we use exact index number measures for both importer and exporter price indexes and use the usual gravity model dependent variable, bilateral trade flows. 
implicit trade barriers are the focus. Gravity equations similar to McCallum's have been estimated to determine the impact of trade unions ${ }^{3}$, monetary unions ${ }^{4}$, different languages, adjacency, and a variety of other factors; all can be improved with our methods. Gravity equations have also been applied to migration flows, equity flows and FDI flows. ${ }^{5}$ Here there is no received theory to apply, consistently or not, but our results suggest the fruitfulness of theoretical foundations.

The remainder of the paper is organized as follows. In Section II we will provide some results based on McCallum's gravity equation. The main new aspect of this section is that we also report the results from the U.S. perspective, comparing interstate trade to state-province trade. In section III we derive the theoretical gravity equation. The main innovation here is to rewrite it in a simple symmetric form, relating bilateral trade to size, bilateral trade barriers and multilateral resistance variables. Section IV discusses the procedure for estimating the theoretical gravity equation, both for a two-country version of the model, consisting of the U.S. and Canada, and for a multi-country version that also includes all other industrialized countries. The results are discussed in section V. Section VI performs sensitivity analysis and the final section concludes.

\section{The McCallum Gravity Equation}

McCallum [1995] estimated the following equation:

$$
\ln x_{i j}=\alpha_{1}+\alpha_{2} \ln y_{i}+\alpha_{3} \ln y_{j}+\alpha_{4} \ln d_{i j}+\alpha_{5} \delta_{i j}+\epsilon_{i j}
$$

Here $x_{i j}$ is exports from region $i$ to region $j, y_{i}$ and $y_{j}$ are gross domestic production in regions $i$ and $j, d_{i j}$ is the distance between regions $i$ and $j$, and $\delta_{i j}$ is a dummy variable equal to one for inter-provincial trade and zero for state-province trade. For the year 1988 McCallum estimated this equation using data for all 10 provinces

\footnotetext{
${ }^{3}$ See Frankel, Jeffrey, Ernesto Stein and Shang-Jin Wei [1997].

${ }^{4}$ Rose [2000] finds that trade among countries in a monetary union is three times the size of trade among countries that are not in a monetary union, holding other trade costs constant.

${ }^{5}$ The first application to migration flows dates from the nineteenth century writings by Ravenstein [1885,1889]. For a more recent application see Helliwell [1997]. Portes and Rey [1998] applied a gravity equation to bilateral equity flows. Brenton et. al. [1999] and Frankel and Wei [1996] have applied the gravity equation to FDI flows.
} 
and for 30 states that account for $90 \%$ of U.S.-Canada trade. In this section we will also report results when estimating (1) from the U.S. perspective. In that case the dummy variable is one for interstate trade and zero for state-province trade. We also report results when pooling all data, in which case there are two dummy variables. The first is one for interprovincial trade and zero otherwise, while the second is one for interstate trade and zero otherwise.

The data are discussed in the Data Appendix. Without going into detail here, a couple of comments are useful. The interprovincial and state-province trade data are from different divisions of Statistics Canada, while the interstate trade data are from the Commodity Flow Survey conducted by the Bureau of the Census. We follow McCallum by applying adjustment factors to the original data in order to make them as closely comparable as possible. All results reported below are for the year 1993, for which the interstate data are available. We follow McCallum and others by only using data for 30 states.

The results from estimating (1) are reported in Table 1. The first three columns report results for respectively (i) state-province and inter-provincial trade, (ii) state-province and inter-state trade, (iii) state-province, inter-provincial and interstate trade. In the latter case there are separate border dummies for within-U.S. trade and within-Canada trade. The final three columns report the same results after imposing unitary coefficients on the GDP variables. This makes comparison with our theoretically based gravity equation results easier because the theory imposes unitary coefficients.

Border - Canada is the exponential of the Canadian dummy variable coefficient, $\alpha_{5}$, which gives us the effect of the border on the ratio of inter-provincial trade to state-province trade after controlling for distance and size. Similarly, Border -US is the exponential of the coefficient on the US dummy variable, which gives the effect of the border on the ratio of inter-state trade to state-province trade after controlling for distance and size.

Four conclusions can be reached from the table. First, we confirm a very large border coefficient for Canada. The first column shows that, after controlling for distance and size, inter-provincial trade is 16.4 times state-province trade. This is only somewhat lower than the border effect of 22 that McCallum estimated based on 1988 data. Second, the U.S. border coefficient is much smaller. The second column tells us that inter-state trade is a factor 1.50 times state-province 
trade after controlling for distance and size. We will show below that this large difference between the Canadian and U.S. border coefficients is exactly what the theory predicts. Third, these border coefficients are very similar when pooling all the data. Finally, the border coefficients are also similar when unitary income coefficients are imposed. With pooled data and unitary income coefficients (last column), the Canadian border coefficient is 14.2 and the U.S. border coefficient is 1.62 .

The bottom of the table reports results when atheoretical remoteness variables are added. We use the definition of remoteness that has been commonly used in the literature following McCallum's paper. The regression then becomes

$$
\ln x_{i j}=\alpha_{1}+\alpha_{2} \ln y_{i}+\alpha_{3} \ln y_{j}+\alpha_{4} \ln d_{i j}+\alpha_{5} \ln R E M_{i}+\alpha_{6} \ln R E M_{j}+\alpha_{7} \delta_{i j}+\epsilon_{i j}
$$

where the remoteness of region $i$ is

$$
R E M_{i}=\sum_{m \neq j} d_{i m} / y_{m}
$$

This variable is intended to reflect the average distance of region $i$ from all trading partners other than $j$. Table 1 shows that adding remoteness indices for both regions changes the border coefficient estimates very little and also has very little additional explanatory power based on the adjusted $R^{2}$.

\section{The Gravity Model}

The empirical literature cited above pays no more than lip service to theoretical justification. We show in this section how taking the theory seriously provides a different model to estimate with a much more useful interpretation.

Anderson [1979] presented a theoretical foundation for the gravity model based on constant elasticity of substitution (CES) preferences and goods that are differentiated by region of origin. Subsequent extensions (Bergstrand [1989,1990], Deardorff [1998]) have preserved the CES preference structure and added monopolistic competition or a Hecksher-Ohlin structure to explain specialization. A contribution of this paper is our manipulation of the CES expenditure system to derive an operational gravity model with an elegantly simple form. On this basis we derive a decomposition of trade resistance into three intuitive components: (i) the bilateral 
trade barrier between region $i$ and region $j$, (ii) $i^{\prime} s$ resistance to trade with all regions, and (iii) $j^{\prime} s$ resistance to trade with all regions.

The first building block of the gravity model is that all goods are differentiated by place of origin. Following Deardorff [1998], we assume that each region is specialized in the production of only one good. ${ }^{6}$ The supply of each good is fixed.

The second building block is identical, homothetic preferences, approximated by a CES utility function. If $c_{i j}$ is consumption by region $j$ consumers of goods from region $i$, consumers in region $j$ maximize

$$
\left(\sum_{i} \beta_{i}^{1 / \sigma} c_{i j}^{(\sigma-1) / \sigma}\right)^{\sigma /(\sigma-1)}
$$

subject to the budget constraint

$$
\sum_{i} p_{i j} c_{i j}=y_{j}
$$

Here $\sigma$ is the elasticity of substitution between all goods, $\beta_{i}$ is a positive distribution parameter, $y_{j}$ is the nominal income of region $j$ residents, and $p_{i j}$ is the price of region $i$ goods for region $j$ consumers. Prices differ between locations due to trade costs that are not directly observable, and the main objective of the empirical work is to identify these costs. Let $p_{i}$ denote the exporter's supply price, net of trade costs, and let $t_{i j}$ be the trade cost factor between $i$ and $j$. Then $p_{i j}=p_{i} t_{i j}$.

We assume that the trade costs are borne by the exporter. We have in mind information costs, design costs and various legal and regulatory costs as well as transport costs. The new empirical literature on the export behavior of firms (Roberts and Tybout [1995]; Bernard and Wagner [1998]) emphasizes the large costs facing exporters. Formally, we assume that for each good shipped from $i$ to $j$ the exporter incurs export costs equal to $t_{i j}-1$ of country $i$ goods. The exporter passes on these trade costs to the importer. The nominal value of exports from $i$ to $j$ ( $j$ 's payments to $i$ ) is $x_{i j}=p_{i j} c_{i j}$, the sum of the value of production at the origin, $p_{i} c_{i j}$ and the trade cost $\left(t_{i j}-1\right) p_{i} c_{i j}$ that the exporter passes on to the

\footnotetext{
${ }^{6}$ With this assumption we suppress finer classifications of goods. Our purpose is to reveal resistance to trade on average, with special reference to the proper treatment of international borders. Resistance to trade does differ among goods, so there is something to be learned from disaggregation.
} 
importer. Total income of region $i$ is therefore $y_{i}=\sum_{j} x_{i j}{ }^{7}$

The nominal demand for region $i$ goods by region $j$ consumers satisfying maximization of (4) subject to (5) is

$$
x_{i j}=\left(\frac{\beta_{i} p_{i} t_{i j}}{P_{j}}\right)^{(1-\sigma)} y_{j},
$$

where $P_{j}$ is the consumer price index of $j$, given by

$$
P_{j}=\left[\sum_{i}\left(\beta_{i} p_{i} t_{i j}\right)^{1-\sigma}\right]^{1 /(1-\sigma)} .
$$

We will refer to this price index as multilateral trade resistance as it depends positively on trade barriers with all trading partners. Market clearance implies:

$$
y_{i}=\sum_{j} x_{i j}=\sum_{j}\left(\beta_{i} t_{i j} p_{i} / P_{j}\right)^{1-\sigma} y_{j}, \quad \forall i .
$$

A tractable gravity model approach may be based on estimating a stochastic version of (6) subject to the constraints (7) and (8). The set of scaled prices $\left\{\beta_{i} p_{i}\right\}$ are solved, up to a factor of proportionality, as implicit functions of the $y$ 's and $t$ 's from the system of market clearing constraints. Given some procedure for identifying the trade barriers, estimation can proceed. But we achieve a very useful simplification by assuming that the trade barriers are symmetric, that is, $t_{i j}=t_{j i}{ }^{8}$ Under symmetry it can be shown that the implicit solution to

$$
\beta_{i} p_{i} P_{i}=\theta_{i}^{1 /(1-\sigma)}, \quad \forall i
$$

\footnotetext{
${ }^{7}$ The model is essentially the same when adopting the 'iceberg melting' structure of the economic geography literature, whereby a fraction $t_{i j}-1$ of goods shipped is lost in transport. The only small difference is that observed f.o.b. trade data do not include transportation costs, while they do include costs that are borne by the exporter and passed on to the importer. When transportation costs are the only trade costs, the observed f.o.b. trade flows are equal to $p_{i} c_{i j}$. The same is the case when the costs are borne by the importer. While we believe that most trade costs are borne by the exporter, particularly for US-Canada trade where formal import barriers are very low, this is not critical to the findings of the paper; the results would be similar when assuming that observed trade flows are equal to $p_{i} c_{i j}$.

${ }^{8}$ There are many equilibria with asymmetric barriers that lead to the same equilibrium trade flows as with symmetric barriers, so that empirically they are impossible to distinguish. In particular, if $\lambda_{i}$ and $\lambda_{j}$ are region specific constants, multiplying $t_{i j}$ by $\lambda_{j} / \lambda_{i} \forall i, j$ leads to the same equilibrium trade flows $\left[p_{i}\right.$ is multiplied by $\lambda_{i}$ and $P_{j}$ is multiplied by $\lambda_{j}$ in (8)]. The product of the trade barriers in different directions remains the same though. If the $\lambda$ 's are
} 
with $\theta_{i}=y_{i} / y^{W}$ the $i t h$ region's share in world income, is a solution to (7)-(8). ${ }^{9}$ (9) is solved not only for relative prices, but also for absolute prices, so it imposes an implicit normalization. Equation (9) has a simple intuition. First, a large $\theta_{i}$ implies a large value of sales, which for a given preference parameter $\beta_{i}$ is induced by a low goods price $p_{i}$. Second, high trade barriers, reflected by high multilateral resistance $P_{i}$, lower demand for region $i$ 's goods, reducing its supply price $p_{i}$.

Substituting (9) into the export demand system (6) yields the gravity equation

$$
x_{i j}=\frac{y_{i} y_{j}}{y^{W}}\left(\frac{t_{i j}}{P_{i} P_{j}}\right)^{1-\sigma} .
$$

An implicit solution for the price indexes as a function of trade barriers can be found by substituting (9) in (7):

$$
P_{j}^{1-\sigma}=\sum_{i} P_{i}^{\sigma-1} \theta_{i} t_{i j}^{1-\sigma} \quad \forall j
$$

Our basic gravity model is (10) subject to (11).

Our gravity equation (10) significantly simplifies expressions derived by Anderson [1979] and Deardorff [1998]. These earlier papers contain a complicated exporter-specific price index term in the denominator. Our implicit solution (9) to the goods market equilibrium conditions allows us to replace that term with the exporter's price index $P_{i}$, which leads to the symmetric form of the gravity equation (10).

The gravity equation tells us that bilateral trade, after controlling for size, depends on the bilateral trade barrier between $i$ and $j$, divided by the product of their multilateral trade resistance. Assume that $\sigma>1$, consistent with empirical results in the literature. It is easy to see why higher multilateral resistance of the importer $j$ raises its trade with $i$. For a given bilateral barrier between $i$ and $j$, higher barriers between $j$ and its other trading partners will reduce the relative

country-specific, but differ across countries, we have introduced asymmetric border barriers across countries, while the product of border barriers remains the same. We can therefore interpret the border barriers we estimate in this paper as an average of the barriers in both directions. Our analysis suggests that inferential identification of the asymmetry is problematic.

${ }^{9}$ Denote our particular solution (combining (7) and (9)) with a *. Substitute (9) into the price index definition $(7)$ to obtain $\left(P_{j}^{*}\right)^{1-\sigma}=\sum_{i} \theta_{i}\left(t_{i j} / P_{i}^{*}\right)^{1-\sigma}$. The same implicit expression for the price indices is obtained by substituting our solution (9) into the market clearing equations (8). We get $y_{i}=\theta_{i} \sum_{j} y_{j}\left(t_{i j} / P_{i}^{*} P_{j}^{*}\right)^{1-\sigma}$, implying $\left(P_{i}^{*}\right)^{1-\sigma}=\sum_{j} \theta_{j}\left(t_{i j} / P_{j}^{*}\right)^{1-\sigma}$. 
price of goods from $i$ and raise imports from $i$. Higher multilateral resistance of the exporter $i$ also raises trade. As discussed above, higher multilateral resistance leads to a lower supply price $p_{i}$. For a given bilateral barrier between $i$ and $j$, this raises the trade level between them.

The gravity model (10) subject to (11) implies that bilateral trade is homogeneous of degree zero in trade costs, where these include the costs of shipping within a region, $t_{i i}$. This follows because the multilateral resistances $P_{i}$ are homogeneous of degree $1 / 2$ in the trade costs. The economics behind the formal result is that the constant vector of real products must still be distributed. The rise in trade costs is offset by the fall in supply prices (they are homogeneous of degree minus $1 / 2$ in trade costs) to permit shipment in the same volume. ${ }^{10}$

The key implication of the theoretical gravity equation is that trade between regions is determined by relative trade barriers. Trade between two regions depends on the bilateral barrier between them relative to average trade barriers that both regions face with all their trading partners. This insight has many implications for the impact of trade barriers on trade flows. Here we will focus on one important set of implications related to the size of countries because they are useful in interpreting the findings in section V. Consider the simple thought experiment of a uniform rise in border barriers between all countries. For simplicity we assume that each region $i$ is a frictionless country. We will discuss three implications of this experiment, which are listed below.

\section{Implication 1}

Trade barriers reduce size-adjusted trade between large countries more than between small countries.

\section{Implication 2}

Trade barriers raise size-adjusted trade within small countries more than within large countries.

\section{Implication 3}

\footnotetext{
${ }^{10}$ The invariance of trade to uniform decreases in trade costs may offer a clue as to why the usual gravity model estimation has not found trade becoming less sensitive to distance over time (Eichengreen and Irwin [1998]).
} 
Trade barriers raise the ratio of size-adjusted trade within country 1 relative to size-adjusted trade between countries 1 and 2 by more the smaller is country 1 and the larger is country 2.

The experiment amounts to a marginal increase in trade barriers across all countries, so $d t_{i j}=d t, i \neq j ; d t_{i i}=0$. Frictionless initial equilibrium implies $t_{i j}=1 \forall i, j$. Differentiating $(11)$ at $t_{i j}=1 \Rightarrow P_{i}=1, \forall i, j$ yields $^{11}$

$$
d P_{i}=\left(\frac{1}{2}-\theta_{i}+\frac{1}{2} \sum_{k} \theta_{k}^{2}\right) d t .
$$

Thus a uniform increase in trade barriers raises multilateral resistance more for a small country than a large country. The reason is that the increase in trade barriers only applies to trade across countries. Trade barriers within countries have not changed. For a very large country multilateral trade resistance is not much affected because the increased trade barriers do not apply to trade within the country. A very small country, on the other hand, faces increased trade barriers with almost the whole world, leading to a large increase in multilateral resistance.

(12) implies that the level of trade between countries $i$ and $j$, after controlling for size, changes by

$$
d\left(x_{i j} \frac{y^{W}}{y_{i} y_{j}}\right)=-(\sigma-1)\left[\theta_{i}+\theta_{j}-\sum_{k} \theta_{k}^{2}\right] d t
$$

This implies that trade between large countries drops more than trade between small countries (Implication 1). While two small countries face a larger bilateral trade barrier, they face the same increase in trade barriers with almost the entire world. Bilateral trade depends on the relative trade resistance $t_{i j} / P_{i} P_{j}$. Since multilateral trade resistance rises much more for small countries than for large countries, relative trade resistance rises less for small countries, so that their

${ }^{11}$ To obtain this expression we differentiate totally at $t_{i j}=1=P_{i}=p_{i}$ to obtain

$$
d P_{j}=\sum_{i} \theta_{i} d t_{i j}-\sum_{i} \theta_{i} d P_{i}+\frac{1}{1-\sigma} \sum_{i} d \theta_{i}
$$

$\sum_{i} d \theta_{i}=0$, since the sum of the shares is equal to one. Multiplying each equation by $\theta_{j}$ and summing using $d t_{i j}=d t, i \neq j, d t_{i i}=0$, we solve for $\sum \theta_{j} d P_{j}=\left(1-\sum \theta_{j}^{2}\right) d t / 2$ and thus $d P_{i}=\left(1 / 2-\theta_{i}+\sum \theta_{j}^{2} / 2\right) d t$. 
bilateral trade drops less. ${ }^{12}$

(12) also implies that trade within a country $i$, after controlling for size, increases by

$$
d\left(x_{i i} \frac{y^{W}}{y_{i} y_{i}}\right)=(\sigma-1)\left[1-2 \theta_{i}+\sum_{k} \theta_{k}^{2}\right] d t .
$$

Therefore trade within a small country increases more than trade within a large country (Implication 2). A rise in multilateral trade resistance implies a drop in relative resistance $t_{i i} / P_{i} P_{i}$ for intranational trade. The drop is larger for small countries that face a bigger increase in multilateral trade resistance.

Implication 3 follows from the previous two. After controlling for size, trade within country $i$ relative to trade between countries $i$ and $j$ rises by

$$
d\left(\frac{x_{i i} / y_{i} y_{i}}{x_{i j} / y_{i} y_{j}}\right)=(\sigma-1)\left[1-\theta_{i}+\theta_{j}\right] d t
$$

The increase is larger the smaller $i$ and the bigger $j$. We already knew from Implication 2 that intranational trade rises most for small countries. From Implication 1 we also know that for a given small country international trade drops most with large countries.

The implications relating to size are much more general than the specifics of the model might suggest. Consider the following example without any reference to gravity equations and multilateral resistance variables. A small economy with two regions and a large economy with 100 regions engage in international trade. All regions have the same GDP. What matters here is not the number of regions, but the relative size of the two economies as measured by total GDP. We only introduce regions in this example because it is illustrative in the context of the US states and Canadian provinces that are the focus of the empirical analysis. Under borderless trade, all regions sell one unit of one good to all 102 regions (including themselves). Now impose a barrier between the small and the large country, reducing trade between the two countries by $20 \%$. Region 1 in the small country then reduces its exports to the large country by 20 . It sells 10 more goods

\footnotetext{
${ }^{12} \mathrm{As}$ is immediately clear from (13), trade between two small countries can even rise after a uniform increase in trade barriers. This is because the pre-barrier prices $p_{i}$ drop more in small countries than in large countries as small countries are more affected by a drop in foreign demand. This makes it more attractive for small countries to trade with each other than with large countries.
} 
to itself and 10 more goods to region 2 in the small country. Trade between the two regions in the small country rises by a factor 11, while trade between two regions in the large country rises by a factor of only 1.004 (an illustration of Implication 2 above). This shows that even a small drop in international trade can lead to a very large increase in trade within a small country. Trade between the two regions in the small country is now 13.75 times trade between regions in both countries, while trade between two regions in the large country is only 1.255 times trade between regions in the two countries (an illustration of Implication 3).

The final step in our theoretical development of the gravity equation is to model the unobservable trade cost factor $t_{i j}$. We follow other authors in hypothesizing that $t_{i j}$ is a loglinear function of observables: bilateral distance $d_{i j}$ and whether there is an international border between $i$ and $j$ :

$$
t_{i j}=b_{i j} d_{i j}^{\rho}
$$

$b_{i j}=1$ if regions $i$ and $j$ are located in the same country. Otherwise $b_{i j}$ is equal to one plus the tariff-equivalent of the border barrier between the countries in which the regions are located. Other investigators have added adjacency and linguistic identity dummy variables to the determinants of trade costs; we suppress these for simplicity.

We can now compare the theoretical gravity equation with that estimated in the empirical literature. The theory implies that

$$
\ln x_{i j}=k+\ln y_{i}+\ln y_{j}+(1-\sigma) \rho \ln d_{i j}+(1-\sigma) \ln b_{i j}-(1-\sigma) \ln P_{i}-(1-\sigma) \ln P_{j}
$$

where $k$ is a constant. The key difference between (17) and equation (1) estimated by McCallum is the two price index terms. The omitted multilateral resistance variables are not orthogonal to the $d_{i j}$ and $b_{i j}$ terms, so they create omitted variable bias when the coefficient of the distance and border variables is interpreted as $(1-$ $\sigma) \rho$ and $(1-\sigma) \ln b_{i j}$. Our multilateral resistance variables bear some resemblance to "remoteness" indexes such as (3) that have been included in gravity equation estimates subsequent to McCallum's paper. But the latter do not include border barriers and even without border barriers the functional form is quite different.

A small difference between the theory and the empirical literature is that the theoretical gravity equation imposes unitary income elasticities. Anderson [1979] 
provided a rationale for earlier (and subsequent) empirical gravity work that estimates non-unitary income elasticities. He allowed for nontraded goods and assumed a reduced form function of the expenditure share falling on traded goods as a function of total income. We already found in section II that imposing unitary income elasticities has little effect on McCallum's border estimates. We will therefore impose unitary income elasticities in most of the analysis, leaving an extension to non-unitary elasticities to sensitivity analysis.

\section{Estimation}

We implement the theory both in the context of a two-country model, consisting of the U.S. and Canada, and a multi-country model that also includes other industrialized countries. The latter approach is obviously more realistic as it takes into account that the US and Canada also trade with other countries. It has the additional advantage that it delivers an estimate of the impact of border barriers

on trade among the other industrialized countries. We first discuss the two-country model and then the multi-country model.

\section{IV.1 Two-Country Model}

In the two-country model we estimate the gravity equation for trade flows among the same 30 states and 10 provinces as in McCallum [1995]. We do not include in the sample the other 21 regions (20 states plus DC), which account for about $15 \%$ of US GDP, and trade flows internal to a state or province. However, in order to compute the multilateral resistance variables for the regions in our sample, we do need to use information on size and distance associated with the other 21 regions and we also need to use information on the distances within regions. We simplify by aggregating the other 21 regions into one region, defining the distance between this region and region $i$ in our sample as the GDP weighted average of the distance between $i$ and each of the 21 regions that make up the new region. There is no simple way to compute distances internal to a region. Fortunately, as we will show in section VI, our results are not very sensitive to assumptions about internal distance. We use the proxy developed by Wei [1996], which is one fourth 
the distance of a region's capital from the nearest capital of another region. ${ }^{13}$

In the two-country model $b_{i j}=b^{1-\delta_{i j}}$, where $b-1$ represents the tariff-equivalent US-Canada border barrier and $\delta_{i j}$ is the same dummy variable as in section II, equal to 1 if $i$ and $j$ are in the same country and zero otherwise.

We estimate a stochastic form of (10). The error term enters additively in the logarithmic form of the gravity equation:

$$
\begin{aligned}
\ln z_{i j} \equiv \ln \left(\frac{x_{i j}}{y_{i} y_{j}}\right)= & k+(1-\sigma) \rho \ln d_{i j}+[(1-\sigma) \ln b]\left(1-\delta_{i j}\right) \\
& -\ln P_{i}^{1-\sigma}-\ln P_{j}^{1-\sigma}+\varepsilon_{i j} .
\end{aligned}
$$

Estimation is subject to the 41 goods market equilibrium conditions, or, equivalently, the 41 conditions (11) that define the price indices $P_{i}$ as a function of the trade barriers. The parameters to be estimated are $k, a_{1}=(1-\sigma) \rho$, and $a_{2}=(1-\sigma) \ln b$. Thus we use the non-linear least squares estimator, which solves

$$
\begin{aligned}
& \min _{k, a_{1}, a_{2}} \sum_{i} \sum_{j \neq i}\left[\ln z_{i j}-k-a_{1} \ln d_{i j}-a_{2}\left(1-\delta_{i j}\right)+\ln P_{i}^{1-\sigma}+\ln P_{j}^{1-\sigma}\right]^{2} \\
& \text { subject to } P_{j}^{1-\sigma}=\sum_{i} P_{i}^{\sigma-1} \theta_{i} e^{a_{1} \ln d_{i j}+a_{2}\left(1-\delta_{i j}\right)} \forall j .
\end{aligned}
$$

The substitution elasticity $\sigma$ always enters in multiplicative form with the trade cost parameters $\rho$ and $\ln b$ in $a_{1}$ and $a_{2}$, and is therefore not identified. ${ }^{14}$

\section{IV.2 Multi-Country Model}

In the multi-country model the world consists of all industrialized countries, a total of 22 countries. $^{15}$ In that case there are 61 regions in our analysis: 30 states, the rest of the US, 10 provinces, and 20 other countries. We will often refer to the 20 additional countries as ROW (rest of the world). In this expanded environment we assume that border barriers $b_{i j}$ may differ for US-Canada trade, US-ROW trade,

\footnotetext{
${ }^{13}$ For the region obtained from the aggregation of the 21 regions, we compute internal distance as $\sum_{i=1}^{21} \sum_{j=1}^{21} s_{i} s_{j} d_{i j}$, where $s_{i}$ is the ratio of GDP in region $i$ to total GDP of the 21-region area.

${ }^{14}$ Identification of $\sigma$ is possible in applications where elements of $t_{i j}$ are directly observable, as with tariffs.

${ }^{15}$ Those are the US, Canada, Australia, Japan, New Zealand, Austria, Belgium-Luxembourg, Denmark, Finland, France, Germany, Greece, Ireland, Italy, Netherlands, Norway, Portugal, Spain, Sweden, Switzerland, UK.
} 
Canada-ROW trade and ROW-ROW trade. We define these respectively as $b_{U S, C A}$, $b_{U S, R O W}, b_{C A, R O W}$ and $b_{R O W, R O W}$.

For consistency with the estimation method in the two-country model, and given our focus on the US-Canada border effect, we will continue to estimate the parameters by minimizing the sum of the squared residuals for the 30 states and 10 provinces. But there are now 3 additional parameters that affect the multilateral resistance variables of the states and provinces: $(1-\sigma) \ln b_{U S, R O W}$, $(1-\sigma) \ln b_{C A, R O W}$, and $(1-\sigma) \ln b_{R O W, R O W}$. We impose three constraints in order to obtain estimates for these parameters. The constraints set the average of the residuals for US-ROW trade, CA-ROW trade and ROW-ROW trade equal to zero. ${ }^{16}$ Formally,

$$
\begin{aligned}
& \sum_{j \in R O W}\left(\varepsilon_{U S, j}+\varepsilon_{j, U S}\right)=0 \\
& \sum_{j \in R O W}\left(\varepsilon_{C A, j}+\varepsilon_{j, C A}\right)=0 \\
& \sum_{i, j \in R O W} \sum_{i \neq j} \varepsilon_{i j}=0
\end{aligned}
$$

Since we only have data on trade between the ROW countries and all of the US, the residuals $\varepsilon_{U S, j}$ and $\varepsilon_{j, U S}$ are defined as the log of bilateral trade between the US and country $j$ minus the log of predicted trade, where the latter is obtained by summing over the model's predicted trade between $j$ and all US regions. The same is done for trade between Canada and countries in ROW. ${ }^{17}$

\footnotetext{
${ }^{16}$ Apart from consistency with the two-country estimation method, there are two reasons why we prefer this estimation method as opposed to minimizing the sum of all squared residuals, including those of the ROW countries. First, border barriers are likely to be different across country pairs for the 20 other industrialized countries. Neither estimation method allows us to identify all these barriers separately, but the method we chose is less sensitive to such differences as we only use information on the average error terms involving the ROW countries. Second, the alternative method of minimizing the sum of all squared residuals has weaker finite sample properties. The US-ROW barrier has a much greater impact on US-ROW trade than on trade among the states and provinces, but US-ROW observations are only $2 \%$ of the sample. If there is only weak spurious correlation between the 1511 error terms for trade among states and provinces and the partial derivatives of the corresponding multilateral resistance terms with respect to the US-ROW barrier, it could significantly affect the estimate of that barrier.

${ }^{17}$ Data on exports from individual states to ROW countries do exist (see Feenstra [1997]), but this is based on information about the location of the exporter, which is often not the location of
} 


\section{Results}

Our goal in this section is three-fold. First, we report results from estimating the theoretical gravity equation. Second, we use the estimated gravity equation to determine the impact of national borders on trade flows. This is done by computing the change in bilateral trade flows after removing the border barriers. Finally, we use the estimated gravity equation to account for the estimated McCallum border parameters. This procedure illustrates the role of the multilateral resistance variables in generating a much smaller McCallum border parameter for the US than for Canada as well as the effect of the omitted variable bias in McCallum's procedure.

\section{V.1 Parameter Estimates}

Table 2 reports the parameter estimates. The estimate of the US-Canada border barrier is very similar in both the two-country model and the multi-country model. In the multi-country model the border barrier estimates are also strikingly similar across country pairs. The barrier between the US and Canada is only slightly lower than between the other 20 industrialized countries, the majority of which is trade among European Union countries. The only border barrier that is a bit higher than the others is between Canada and the ROW countries.

As discussed above, we can only estimate $(1-\sigma) \ln b$. One would need to make an assumption about the elasticity of substitution $\sigma$ in order to obtain an estimate of $b-1$, the ad valorem tariff equivalent of the border barrier. The model is of course highly stylized in that there is only one elasticity. In reality some goods may be perfect substitutes, with an infinite elasticity, while others are weak substitutes. Hummels [1999] obtains estimates for the elasticity of substitution within industries. The results depend on the disaggregation of the industries. The average elasticity is respectively 4.8, 5.6 and 6.9 for 1-digit, 2-digit and 3-

the plant where the goods are produced. The International Trade Division and the Input Output Divisions of Statistics Canada both report data on trade between provinces and the rest of the world. The data from the IO Division are considered more reliable, but only the IT division reports trade with individual countries. The differences between the total export and import numbers reported by both divisions are often very large (almost a factor 8 difference for imports by Prince Edward Island). 
digit industries. For further levels of disaggregation the elasticities could be much higher, with some goods close to perfect substitutes. ${ }^{18}$ It is therefore hard to come up with an appropriate average elasticity. To give a sense of the numbers though, the estimate of -1.58 for $(1-\sigma) \ln b_{U S, C A}$ in the multi-country model implies a tariff equivalent of respectively $48 \%, 19 \%$ and $9 \%$ if the average elasticity is 5,10 and 20 .

It is also noteworthy that the estimated distance elasticity $(1-\sigma) \rho$, equal to about -0.8 for both the two-country and multi-country models, is substantially lower than the -1.35 coefficient based on estimating McCallum's regression for 1993 data (first column Table 1). Grossman [1998] has criticized as unrealistically large the -1.42 distance coefficient that McCallum estimated for 1988 data. Adding atheoretical remoteness variables to McCallum's regression, as in Helliwell [1998], leads to an even larger distance coefficient of -1.59 . In contrast, adding the multilateral resistance variables reduces the distance elasticity substantially.

The last three rows of Table 2 report the average error terms for interstate, interprovincial and state-province trade. Particularly for the multi-country model they are close to zero. The average percentage difference between actual trade and predicted trade in the multi-country model is respectively $6 \%,-2 \%$ and $-4 \%$ for interstate, interprovincial and state-province trade. The largest error term in the two-country model is for interprovincial trade, where on average actual trade is $17 \%$ lower than predicted trade. ${ }^{19}$

\section{V.2 Impact of the Border on Bilateral Trade}

We now turn to the implications of the estimated border barriers for bilateral trade flows. We will consider the ratio of trade flows with border barriers to that under

\footnotetext{
${ }^{18}$ For example, for a highly homogeneous commodity such a silver bullion, Feenstra [1994] estimates a 42.9 elasticity of substitution among varieties imported from 15 different countries.

${ }^{19}$ The $\bar{R}^{2}$ is respectively 0.43 and 0.45 for the two-country and multi-country model, which is somewhat lower than the 0.55 for the McCallum equation with unitary elasticities (last column Table 1). This is not a test of the theory though because McCallum's equation is not theoretically grounded. It also does not imply that multilateral resistance does not matter; the dummies in McCallum's equation capture the average difference in multilateral resistance of states and provinces. With a higher estimate of internal distance, the $\bar{R}^{2}$ from the structural model becomes quite close to that in the McCallum equation. It turns out though that internal distance has little effect on our key results (section VI).
} 
borderless trade. Appendix B discusses how we compute the equilibrium after removing all border barriers. It turns out that we need to know the elasticity $\sigma$ in order to solve for the free trade equilibrium. This is because the new income shares $\theta_{i}$ depend on relative prices, which depend on $\sigma$. We set $\sigma=5$, but we will show in the sensitivity analysis section that results are almost identical for other elasticities. The elasticity $\sigma$ plays no role other than to affect the equilibrium income shares a little.

In what follows we define the "average" of trade variables and multilateral resistance variables as the exponential of the average logarithm of these variables, consistent with McCallum [1995]. ${ }^{20}$

The multilateral resistance variables are critical to understanding the impact of border barriers on bilateral trade and understanding what accounts for the McCallum border parameters. Defining regions in the US, Canada and ROW as three sets, Table 3 reports the average $P^{\sigma-1}$ for regions in each of these sets. The results are shown both with the estimated border barrier and under borderless trade. As discussed in section III, based on the model we would expect border barriers to lead to a larger increase of multilateral resistance in small countries than in large countries. This is exactly what we see in Table $3 . P^{\sigma-1}$ rises by $12 \%$ for US states, while it rises by a factor 2.44 for Canadian provinces. The number is intermediate for ROW countries, whose size is also intermediate. The Canadian border creates a barrier between provinces and most of its potential trading partners, while states face no border barriers with the rest of the large US economy. Multilateral resistance therefore rises much more for provinces than for states. $^{21}$

\footnotetext{
${ }^{20} \mathrm{McC}$ Callum's border effect is the difference between the average logarithm of bilateral trade among regions in the same country and the average logarithm of bilateral trade of regions in different countries. This is converted back to levels by taking the exponential. Among a set of regions, bilateral trade between two regions is therefore considered to be average when the logarithm of bilateral trade is average within the set.

${ }^{21}$ We find that there is little relationship between the theoretical multilateral resistance variables for the 22 countries and the consumer price indices from the Penn World Tables. This may be because we have set the border barriers the same for all ROW countries. There are also many factors affecting consumer price levels that are not in the model, most importantly non-traded goods. Finally, trade costs do not necessarily have to show up in consumer prices. For example, the same gravity equation can be derived when trade costs enter through the utility function.
} 
Even under borderless trade multilateral resistance is substantially higher for provinces than for states. Distances are somewhat larger on average between the US and Canada than within them. This affects multilateral resistance for provinces more than for states as most potential trading partners of the provinces are outside their country, while for the states they are inside the country. This is again the result of the small size of the Canadian economy.

Table 4 reports the impact of border barriers on bilateral trade flows among and within each of the three sets of regions (US, CA, ROW). Size is controlled for by multiplying the bilateral trade numbers by $y^{W} /\left(y_{i} y_{j}\right)$. Letting a tilde denote borderless trade, the ratio of average trade between regions in sets $h$ and $k(h, k=$ $U S, C A, R O W)$ with and without border barriers is

$$
b_{h k}^{1-\sigma}\left(\frac{P_{h}^{\sigma-1}}{\tilde{P}_{h}^{\sigma-1}}\right)\left(\frac{P_{k}^{\sigma-1}}{\tilde{P}_{k}^{\sigma-1}}\right)
$$

where $P_{h}^{\sigma-1}$ refers to the average of regions in that set. We can therefore break down the impact of border barriers on trade into the impact of the bilateral border barrier and the impact of border barriers on multilateral resistance of regions in both sets. To the extent that border barriers raise average trade barriers faced by an importer and an exporter (multilateral resistance), it dampens the negative impact of the bilateral border barrier on trade between the two countries. In what follows we will focus on the numbers for the more realistic multi-country model.

Implication 2 of the theory that cross-country trade barriers raise trade within a country more for small than for large countries is strongly confirmed in Table 4. The table reports a spectacular factor 6 increase in interprovincial trade due to borders, while interstate trade rises by only $25 \%$. The larger increase in multilateral resistance of the provinces leads to a bigger drop in relative trade resistance $t_{i i} / P_{i} P_{i}$ for trade within Canada than within the US, explaining the large increase in interprovincial trade.

Table 4 also reports that borders reduce trade between the US and Canada to a fraction 0.56 of that under borderless trade, or by $44 \%$. Trade among ROW countries is reduced by $29 \%$. The bilateral border barrier itself implies an $80 \%$ drop in trade between states and provinces, but increased multilateral resistance, particularly for provinces, raises state-province trade by a factor 2.72 . While US goods have become more expensive for Canada due to the border barrier, the goods 
of almost all trading partners of the provinces have become more expensive. This significantly moderates the negative impact on US-Canada trade.

It may seem somewhat surprising that trade between the ROW countries drops somewhat less than between the US and Canada, particularly because the estimates in Table 2 imply a slightly lower US-Canada border barrier. But it can be understood in the context of Implication 1 from the theory that border barriers have a bigger effect on trade between countries the larger their size. For the same border barriers US-Canada trade would have dropped much less if the US were a much smaller country. This also explains why trade between the US and the ROW countries drops somewhat more than between the US and Canada. Canada is even smaller than the average ROW country. Based on size alone one would expect trade between Canada and the ROW countries to drop less than between Canada and the US, but this is not the case as a result of the higher trade barrier between Canada and the ROW countries.

\section{V.3 Intranational Trade Relative to International Trade}

McCallum aimed to measure the impact of borders on intranational trade (within Canada) to international trade (between US and Canada). In this section we will show that the large McCallum border parameter for Canada is due to a combination of (i) the relative small size of the Canadian economy and (ii) omitted variables bias.

The impact of border barriers on intranational relative to international trade follows immediately from Table 4 and is reported in the first row of Table 5 . The multi-country model implies that national borders lead to trade between provinces that is a factor 10.7 larger than between states and provinces. In contrast, border barriers raise trade between states by only a factor 2.24 relative to trade between states and provinces. This is exactly as anticipated by Implication 3 of the theory. It is the result of the relatively small size of Canada, leading to a factor 6 increase in trade between the provinces. The small change in trade between US states leads to a correspondingly much smaller increase in intranational to international trade for the US.

This is only part of the explanation for the large McCallum border parameter

for Canada. The other part is the result of omitted variables bias. In order to see 
this, rewrite the theoretical gravity equation as

$$
\ln x_{i j}=k+\ln y_{i}+\ln y_{j}+\rho(1-\sigma) \ln d_{i j}+R_{i j}+\epsilon_{i j}
$$

where

$$
R_{i j}=(1-\sigma) \ln b_{i j}-(1-\sigma) \ln P_{i}-(1-\sigma) \ln P_{j}
$$

$R_{i j}$ measures the sum of all trade resistance terms with the exception of the bilateral distance term. Other than allowing for non-unitary income elasticities, which we already saw makes little difference, McCallum estimated (20), but replaced $R_{i j}$ with a dummy variable that is 1 for interprovincial trade and 0 for state-province trade. In the context of the theory we can therefore interpret McCallum's border parameter for Canada as the average of $R_{i j}$ for interprovincial trade minus the average for state-province trade, and similarly for the US. ${ }^{22}$ Taking the exponential for comparison with McCallum's headline number, we get (following the notation of section II)

$$
\text { Border }_{\text {Canada }}=\left(b_{U S, C A}\right)^{\sigma-1} \frac{P_{C A}^{\sigma-1}}{P_{U S}^{\sigma-1}}
$$

Similarly,

$$
\operatorname{Border}_{U S}=\left(b_{U S, C A}\right)^{\sigma-1} \frac{P_{U S}^{\sigma-1}}{P_{C A}^{\sigma-1}}
$$

The theoretical McCallum border parameters are reported in the second row of Table 5. For the multi-country model the border parameters are 14.8 for Canada and 1.63 for the US. This corresponds closely to the 14.2 and 1.62 parameters reported in the last column of Table 1 when estimating McCallum's regression with unitary income coefficients. The much higher Canadian multilateral resistance term, $P_{C A}^{\sigma-1}$, than the US multilateral resistance term, $P_{U S}^{\sigma-1}$, blows up the border effect for Canada, while dampening it with the same factor for the US.

A comparison of rows 1 and 2 of Table 5 shows that McCallum's measure for Canada overstates our consistent estimate of the impact of borders on intranational trade relative to international trade. The reason is that in the correct measure of the impact of borders on intranational relative to international trade, the multilateral resistance terms in (21) and (22) are replaced by the ratio of multilateral

\footnotetext{
${ }^{22}$ We will take the average over all trade pairs, even though for a few state-province pairs and state-state pairs no trade data exist. Taking the average only over pairs for which trade data exist leads to almost identical numbers.
} 
resistance with border barriers relative to that without border barriers. McCallum's measure would have implied a Border parameter larger than 1 for Canada even in the absence of border barriers because of the higher multilateral resistance of provinces than states due to distance alone.

There is also a literature that has estimated the impact of borders on domestic trade relative to international trade for a wide range of other OECD countries. This literature is based on McCallum type regressions, often with atheoretical remoteness variables added, using international trade data combined with an estimate of total domestic trade in each of the countries. The findings from this literature can be compared to the theory. Based on the estimated multi-country model, international trade among the ROW countries drops to a fraction 0.71 of that under free trade, while intranational trade rises on average by a factor 3.8. This implies a factor $5.4(3.8 / 0.71)$ increase in intranational trade relative to international trade, which falls within the range of estimates of about 2.5 to 10 that have been reported in the empirical literature. For example, Helliwell [1998] reports a factor 5.7 for 1992 data, estimating (2) with the atheoretical remoteness variables (3) included. Our findings suggest that the trade home bias reported in this literature is primarily a result of the large increase in intranational trade. International trade drops by only $29 \%$ as a result of borders. Intranational trade rises so much for the same reason that interprovincial trade rises so much in Canada. Most countries are relatively small as a fraction of the world economy.

\section{Sensitivity Analysis}

Table 6 reports the results from a variety of sensitivity analysis. In order to save space we only report the key variables of interest, the impact of borders on trade and the McCallum border parameter. For comparison we report in column (i) results from the base regression.

Column (ii) assumes a higher elasticity of substitution $\sigma=10$ (in the benchmark $\sigma=5$ ). This has no impact on the regression itself but, as discussed in section V.2, it affects somewhat the equilibrium when removing the border barrier. It is clear though from column (ii) that the difference is negligible. The same is the case when we lower $\sigma$ to 2 or raise it 20 (not reported). The insensitivity to $\sigma$ is encouraging as there is little agreement about the precise magnitude of this 
parameter.

Columns (iii) and (iv) report results when we respectively double and halve our measure of distance internal to states, provinces and the other industrialized countries. While we have used the proxy by Wei [1996] that has been commonly used in the literature, this is only a rough estimate. The correct measure depends a lot on a region's geography. ${ }^{23}$ Helliwell [1998] finds that results are very sensitive to internal distance when applying a McCallum gravity equation to international and intranational trade of OECD countries. Halving internal distances reduces the border effect by about half, while doubling internal distances more than doubles it. In contrast, columns (iii) and (iv) of Table 6 show that doubling or halving internal distances has very little effect on our results. A big advantage of the USCanada data set is that the intranational trade data are for interstate trade and interprovincial trade. It is relatively easy to measure distances between states and between provinces. We do not use data on trade internal to a state or province, for which distance is hard to measure. In our regression internal distance only matters to the extent that it affects multilateral resistance.

Column (v) reports results when we do not use data on interstate trade. The reason for doing so is that McCallum did not use interstate trade data and we do not want to leave the impression that the interstate data set is critical to our findings. The results reported in column (v) are somewhat different from those based on the benchmark regression, but they are qualitatively identical. The reported impact of borders on trade levels is not statistically different from that reported under the benchmark regression. If anything it reinforces our key finding of a moderate impact of borders on international trade. The multi-country model tells us that US-Canada trade is reduced by $37 \%$ as a result of border barriers, while trade among other industrialized countries is reduced by $17 \%$.

Columns (vi) and (vii) report results when allowing for non-unitary income elasticities. Anderson [1979] allowed for non-unitary income elasticities by modeling the fraction spent on tradable goods. We have used total GDP, from hereon $Y$, as an estimate of tradables output $y$ in the model. But in reality GDP also includes non-tradables. Anderson [1979] assumed that a fraction $\phi$ of total income is spent on tradables, so that spending on tradables is $\phi Y$. Because of balanced

\footnotetext{
${ }^{23}$ For example, it is possible that most trade takes place within one industrial area, in which case the appropriate measure of internal distance could be close to zero.
} 
trade, output of tradables must also be $\phi Y$. Anderson allowed $\phi$ to be a function of both $Y$ and $N$ (population). Column (vi) reports results when $\phi=Y^{\alpha}$, so that bilateral trade is equal to $Y_{i}^{1+\alpha} Y_{j}^{1+\alpha}$ times the trade resistance terms. While this introduces non-unitary income elasticities, as in McCallum [1995], we should stress that there is no clear theoretical foundation for specifying the fraction spent on tradables as $Y^{\alpha}$. Column (vii) reports results when $\phi=(Y / N)^{\alpha}$. In that case bilateral trade is equal to $Y_{i}^{1+\alpha} Y_{j}^{1+\alpha} N_{i}^{-\alpha} N_{j}^{-\alpha}$ times the trade resistance terms. This assumption has somewhat more solid theoretical grounding. The well known Balassa-Samuelson effect tells us that regions with higher productivity in the tradables sector will have a higher relative price of non-tradables, which should raise the fraction spent on tradables. To the extent that $Y / N$ proxies for productivity in the tradables sector, one might expect $\alpha$ to be positive. This is indeed what we find in the estimation. ${ }^{24}$ The results reported in Table 6 , while they change somewhat from the base regression, are still qualitatively the same. If anything, we find that the impact of borders on international trade is reduced somewhat further when $\phi$ is a function of $Y / N$.

The final column in Table 6 reports results for the multi-country model when we estimate all parameters by minimizing the sum of all squared residuals, including the ROW-ROW, US-ROW and CA-ROW residuals. As discussed above, an important reason for not doing so in the first place is that this estimation procedure has weaker finite sample properties, primarily because there are relatively few US-ROW and CA-ROW observations. One implausible finding, not reported in Table 6, is that the US-ROW barrier now becomes lower than the US-CA border barrier, with $(1-\sigma) \ln b$ of respectively -0.88 and -1.48 . Nonetheless the results reported in Table 6, the impact of borders on trade and the McCallum parameters, remain quite close to those under the benchmark regression.

As a final form of sensitivity analysis, not reported in Table 6, we have estimated the model when replacing the multilateral resistance terms with region dummies. This is only feasible in the two-country model. If the model is correct, this should lead to consistent estimates, although the estimator from the structural model is more efficient. The key parameter $(1-\sigma) \ln b$ does not change much. The distance parameter $(1-\sigma) \rho$ drops from -0.79 in the structural model to -1.25 .

\footnotetext{
${ }^{24}$ For example, in the multi-country model we find $\alpha=1.07$, and similar for the two-country model. When $\psi=Y^{\alpha}$, we find that $\alpha$ is about 0.3 for both models.
} 
This suggests that internal distances are larger than assumed when estimating the structural model. Raising the benchmark internal distances leads to a more negative estimate of $(1-\sigma) \rho$ in the structural model. It also raises the adjusted $R^{2}$ and leads to a higher correlation between the region dummies and the theoretical multilateral resistance terms. Fixed costs of transportation may provide a justification for higher internal distances. Using the estimates of $(1-\sigma) \ln b$ and $(1-\sigma) \rho$ based on the fixed effects estimation, we obtain results quite close to those in Tables 4 and 5 when we substantially raise internal distances.

Overall we can therefore conclude that the results from the benchmark regression are robust to a wide range of sensitivity analysis.

\section{Conclusion}

By taking the gravity model seriously, we have resolved the border puzzle: borders reduce bilateral national trade levels by plausible though substantial magnitudes. The results of previous studies that imply enormous border effects are explicable in terms of our model:(i) they considered the effect of the border on the ratio intranational to international trade, (ii) this border effect is inherently large for small countries, and (iii) omitted variables biased the estimated border effect upwards.

Our findings suggest the desirability of basing gravity equation estimation on the theory, both in terms of estimation and interpretation. The approach can easily be applied to determine the effect of other institutions, such as currency unions, on bilateral trade flows. The basic gravity equation model as we have described it is very simple and can be generalized along various dimensions, for example by allowing for industry-specific barriers and substitution elasticities. We suspect though that the key aspect of the gravity model, the dependence of trade on both bilateral and multilateral resistance, will hold up under a wide range of generalizations. 


\section{Appendix A: The Data}

The paper uses data on trade, distances, GDP and population for states, provinces, and 20 other industrialized countries. Before turning to a detailed discussion of the trade data, we describe the sources of the other data first. Great circle distances are computed using the longitude and latitude of states, provinces and other countries, obtained from the web site http://www.indo.com/distance/. GDP data are from Statistics Canada for the provinces, the Bureau of Economic Analysis for the states, and from the IMF's International Financial Statistics for the 20 other industrialized countries. Population data are from the Bureau of the Census for the states. For provinces and the other industrialized countries the source is the same as for GDP.

The paper combines four trade datasets: interprovincial merchandise trade from the Input-Output Division of Statistics Canada; province-trade merchandise trade from the International Trade Division of Statistics Canada; interstate commodity flows from the Commodity Flow Survey by the U.S. Census; and merchandise trade among the other industrialized countries from the IMF's Direction of Trade Statistics. It should be said from the outset that these datasets use concepts that are different from each other and adjustments are necessary in order to make them more compatible.

McCallum [1995] combines the first two data sources listed above. The IO Division, which collects the interprovincial trade data, also collects data on trade between each province and the rest of the world. Those data net out exports and imports that are en route to and from other provinces. The trade data from the IT Division, on the other hand, are based on customs data, for which the original source and final destination of shipments are not known. There is a nice discussion of these issues in Anderson and Smith [1999a,b]. Because the data of the IO Division are more reliable, McCallum multiplies the state-province trade flows from the IT Division by the ratio of trade of each province with the rest of the world from the IO and IT sources. Helliwell [1998] makes the same adjustment, but at the more detailed level of 27 individual industries. In this paper we use the data with the more detailed adjustment by Helliwell. Data are available for all 90 interprovincial pairs, while they are available for 589 of the 600 state-province pairs (bilateral flows between 10 provinces and 30 states). 
For the year 1993 the Commodity Flow Survey (CFS) by the U.S. Census Bureau provides data on within-state and cross-state shipments. The data set and methodology is described in detail in the Bureau of Transportation web site http://www.bts.gov/ntda/cfs/. The data consists of shipments by domestic establishments in manufacturing, wholesale, mining and selected retail establishments. The survey covers 200,000 representative establishments out of a total of about 800,000. Four times per year, during a two-week period, the surveyed establishments were asked to report the value and volume of shipments, as well as the origin and destination addresses. There are three important differences between these shipments data and the merchandise trade data. First, while merchandise trade data only measure shipments from source to final user, the commodity flow data include all shipments. For example, a product may be shipped from a manufacturing plant to a warehouse and from there to a retailer. Second, goods that are intended for exports, but are first shipped domestically (e.g. to a harbor), are included in domestic shipments. Similarly, goods that are imported are measured once they are shipped from the port of entry to another domestic destination. Third, while the Commodity Flow Survey provides extensive coverage of the manufacturing sector, which is by far the most important goods producing sector, it excludes agriculture and part of mining.

As a result of these inconsistencies, an adjustment is made to the CFS data. The CFS data are scaled down by the ratio of total domestic merchandise trade to total domestic shipments from the CFS. Following Helliwell $(1997,1998)$ and Wei (1996), total domestic merchandise trade is approximated as gross output in mostly goods producing sectors, minus merchandise exports. The goods producing sectors are defined as the sum of agriculture, mining and manufacturing. Using this methodology, total domestic U.S. merchandise trade was $\$ 3,025$ bln. in 1993 , while shipments in the CFS total to $\$ 5,846 \mathrm{bln}$. The CFS data are therefore scaled down by $3025 / 5846$. Of the total 870 trade pairs among the 30 states in the sample, data are available for 832 pairs.

There are several reasons to believe that the adjusted U.S. trade data are not so bad. First, for both the two-country model and the multi-country model the estimated model coefficients are similar when estimating the model without the use of interstate data (an experiment considered in sensitivity analysis), and the difference is not statistically significant. Second, the average squared error term is 
smaller for the interstate data than for the interprovincial data, respectively 0.48 and 1.40 in the multi-country model. This is not the result of the dominance of interstate trade data. When estimating the multi-country model without interstate trade data, the average squared error term of interprovincial data remains 1.44. Consistent with that, Table 1 also reports a higher $\bar{R}^{2}$ when estimating McCallum's equation for the US (0.86) than for Canada (0.77).

We do not pretend to have solved all measurement problems with the adjustment factor applied to the U.S. commodity flow data. As discussed above, the data used in the original McCallum study are not without measurement problems either, with even much larger adjustment factors applied to the original stateprovince data. These data nonetheless remain by far the best currently available to study the impact of borders on trade. Moreover, as reported in the sensitivity analysis, the key findings of this paper do not rely on the US trade dataset.

\section{Appendix B: Solution to the Borderless Trade Equilibrium}

To solve for the borderless trade equilibrium of the model we set $b_{i j}=1 \forall i, j$. When solving for the new equilibrium prices $p_{i}$ from (9), or alternatively for the price indices $P_{i}$ from ( 11 ), we need to take into account that the income shares $\theta_{i}$ change. Let a 1 superscript denote the 'no borders' equilibrium with a 0 superscript denote the estimated model with borders present. Since quantities produced are assumed fixed, $y_{i}^{1}=\left(p_{i}^{1} / p_{i}^{0}\right) y_{i}^{0}$. We observe $y_{i}^{0}$ and have solved for $p_{i}^{0}$. The new income shares $\theta_{i}^{1}$ then become functions of the new prices $p_{i}^{1}$ that are being solved.

While equilibrium trade flows with border barriers can be computed using only the estimated trade cost parameters $(1-\sigma) \ln b_{i j}$ and $(1-\sigma) \rho$, we need to know the elasticity $\sigma$ in order to compute equilibrium trade flows under borderless trade. In the equilibrium with border barriers we can solve for $p_{i}^{1-\sigma} \forall i$ as a function of the estimated trade cost parameters. This determines the equilibrium $P_{i}^{1-\sigma} \forall i$, which determines equilibrium trade flows. But in the borderless trade equilibrium the $p_{i}^{1-\sigma}$ also depend on the income shares $\theta_{i}$, which are functions of the prices $p_{i}$. We therefore need to know $\sigma$ in order to solve for $p_{i}^{1-\sigma}$. 


\section{References}

Anderson, James E. "A Theoretical Foundation for the Gravity Equation", American Economic Review, 1979, 69(1), pp. 106-116.

Anderson, James E. and Douglas Marcouiller, 'Trade, Insecurity and Home Bias: An Empirical Investigation', NBER Working Paper No. 7000, March, 1999.

Anderson, Michael A. and Smith, Stephen L.S. "Canadian Provinces in World Trade: Engagement and Detachment." Canadian Journal of Economics, February 1999a, 32(1), pp. 23-37.

-, "Do National Borders Really Matter? Canada-US Regional Trade Reconsidered." Review of International Economics , 1999b, 7(2), pp. 219-227.

Bergstrand, Jeffrey H., "The Gravity Equation in International Trade: Some Microeconomic Foundations and Empirical Evidence," Review of Economics and Statistics, 1985, 67:3, August, pp. 474-81.

," The Generalized Gravity Equation, Monopolistic Competition, and the Factor-Proportions Theory in International Trade," Review of Economics and Statistics, 1989, 71:1, February, pp. 143-53.

, "The Heckscher-Ohlin-Samuelson Model, the Linder Hypothesis and the Determinants of Bilateral Intra-Industry Trade," The Economic Journal, December 1990, 100, 1216-29.

Brenton, Paul, Francesca Di Mauro and Matthias Lucke. "Economic Integration and FDI: An Empirical Analysis of Foreign Investment in the EU and in Central and Eastern Europe," Empirica, 1999, 26(2), pp. 95-121.

Bernard, Andrew and Joachim Wagner, 1998, "Export Entry and Exit by German Firms", NBER Working Paper No. W6538.

Chen, Natalie A., "Intra-national Versus International Trade in the European Union: Why Do National Borders Matter?", Mimeo, ECARES, Universite Libre de Bruxelles, April 2000.

Deardorff, Alan V. "Determinants of Bilateral Trade: Does Gravity Work in a Neoclassical World?," in Jeffrey A. Frankel ed., The Regionalization of the World Economy, University of Chicago for the NBER, 1998, pp. 7-32.

Eichengreen, Barry and Douglas A. Irwin, "The Role of History in Bilateral Trade Flows", in Jeffrey A. Frankel ed., The Regionalization of the World Economy, University of Chicago for the NBER, 1998, pp. 33-57. 
Evans, Carolyn L. "National Border Effects and Heterogeneous Fixed Costs of International Trade" Mimeo, Federal Reserve Bank of New York, 2000a.

-, "The Economic Significance of National Border Effects." Mimeo, Federal Reserve Bank of New York, 2000b.

Feenstra, Robert C., "New Product Varieties and the Measurement of International Prices", American Economic Review, 1994, 84(1), 157-177.

-, "U.S. Exports, 1972-1994: With State Exports and other U.S. Data", NBER Working Paper 5990.

Frankel, Jeffrey A. and Shang-Jin Wei. "ASEAN in a Regional Perspective" UC Berkeley Working Paper C96-074, November 1996.

Frankel, Jeffrey, Ernesto Stein and Shang-jin Wei (1997), "Continental Trading Blocs: Are They Natural or Supernatural?" in Jeffrey A. Frankel ed., The Regionalization of the World Economy, University of Chicago for the NBER, 1998, pp. 91-113.

Grossman, Gene, comment on Alan V. Deardorff, 'Determinants of Bilateral Trade: Does Gravity Work in a Neoclassical World?' in Jeffrey A. Frankel ed., The Regionalization of the World Economy, University of Chicago for the NBER, 1998, pp. 29-31.

Haveman, Jon and Hummels, David. "Alternative Hypotheses and the Volume of Trade: Evidence on the Extent of Specialization," Mimeo, University of Chicago.

Head, Keith and John Ries. "Armington versus Krugman: A Test of Two Trade Models" Mimeo, University of British Columbia, 1999.

Helliwell, John F., "Do National Boundaries Matter for Quebec's Trade?", Canadian Journal of Economics, 29, 1996, pp. 507-22. , "National Borders, Trade and Migration." Pacific Economic Review, 1997, 2:3, pp. 165-185.

-, How Much Do National Borders Matter?, Washington, D.C.: The Brookings Institution, 1998.

Helliwell, John F. and McCallum, John. "National Borders Still Matter for Trade," Policy Options, 16, 1995, pp. 44-48.

Helliwell, John F. and Verdier, Genevieve. "Comparing Interprovincial and Intraprovincial Trade Densities." Mimeo, University of British Columbia, 2000.

Hillberry, Russell. "Regional Trade and the Medicine Line: The National Border Effect in U.S. Commodity Flow Data," Journal of Borderlands Studies, Fall 1998, 8(2), pp. 1-17.

-, "Explaining the Border Effect: What Can We Learn from Disaggregated Commodity Flow Data?", Mimeo, ITC, 1999.

Hummels, David. "Toward a Geography of Trade Costs", Mimeo, Purdue University, 
1999.

McCallum, John. "National Borders Matter: Canada-U.S. Regional Trade Patterns." American Economic Review, June 1995, 85(3), pp. 615-623.

Messinger, Hans. "Interprovincial Trade Flows of Goods and Services." Canadian Economic Observer, October 1993, 3.8:3.14.

Obstfeld, Maurice and Ken Rogoff. "The Six Major Puzzles in International Macroeconomics. Is There a Common Cause?", NBER Working Paper 7777, July 2000.

Portes, Richard and Helene Rey. "The Euro and International Equity Flows" Journal of the Japanese and International Economies, 1998, 12, 406-423.

Ravenstein, E.G. "The Laws of Migration." Journal of the Royal Statistical Society, 1885, 48, pp. 167-235.

-, "The Laws of Migration." Journal of the Royal Statistical Society, 1889, 52, pp. 167-235.

Roberts, Mark and James Tybout (1997), "The Decision to Export in Colombia: An Empirical Model of Entry with Sunk Costs", American Economic Review, 87, 545564.

Rose, Andrew K., "One Money, One Market: Estimating the Effect of Common Currencies on Trade", Economic Policy, 2000, 30, 7-45.

Trefler, Daniel. "The Case of the Missing Trade and Other Mysteries", American Economic Review, 85, 1029-46.

Wei, Shang-Jin. "Intra-national versus Inter-national Trade: How Stubborn are Nations in Global Integration?" NBER Working Paper 5531, 1996.

Wolf, Holger. "(Why) Do Borders Matter For Trade?", in Gregory Hess and Eric van Wincoop, eds., Intranational Macroeconomics, Cambridge University Press, Cambridge, 2000, pp. 112-128. 


\begin{tabular}{|c|c|c|c|c|c|c|}
\hline \multirow[b]{3}{*}{ Data: } & \multicolumn{3}{|c|}{ McCallum Regressions } & \multicolumn{3}{|c|}{ Unitary Income Elasticities } \\
\hline & (i) & (ii) & (iii) & (iv) & $(\mathrm{v})$ & (vi) \\
\hline & $\begin{array}{l}\text { CA-CA } \\
\text { CA-US }\end{array}$ & $\begin{array}{l}\text { US-US } \\
\text { CA-US }\end{array}$ & $\begin{array}{l}\text { US-US } \\
\text { CA-CA } \\
\text { CA-US }\end{array}$ & $\begin{array}{l}\text { CA-CA } \\
\text { CA-US }\end{array}$ & $\begin{array}{l}\text { US-US } \\
\text { CA-US }\end{array}$ & $\begin{array}{l}\text { US-US } \\
\text { CA-CA } \\
\text { CA-US }\end{array}$ \\
\hline \multicolumn{7}{|l|}{ Independent Variable } \\
\hline $\ln y_{i}$ & $\begin{array}{l}1.22 \\
(0.04)\end{array}$ & $\begin{array}{c}1.13 \\
(0.03)\end{array}$ & $\begin{array}{c}1.13 \\
(0.03)\end{array}$ & 1 & 1 & 1 \\
\hline $\ln y_{j}$ & $\begin{array}{l}0.98 \\
(0.03)\end{array}$ & $\begin{array}{l}0.98 \\
(0.02)\end{array}$ & $\begin{array}{l}0.97 \\
(0.02)\end{array}$ & 1 & 1 & 1 \\
\hline $\ln d_{i j}$ & $\begin{array}{l}-1.35 \\
(0.07)\end{array}$ & $\begin{array}{l}-1.08 \\
(0.04)\end{array}$ & $\begin{array}{l}-1.11 \\
(0.04)\end{array}$ & $\begin{array}{l}-1.35 \\
(0.07)\end{array}$ & $\begin{array}{l}-1.09 \\
(0.04)\end{array}$ & $\begin{array}{l}-1.12 \\
(0.03)\end{array}$ \\
\hline Dummy - Canada & $\begin{array}{c}2.80 \\
(0.12)\end{array}$ & & $\begin{array}{c}2.75 \\
(0.12)\end{array}$ & $\begin{array}{l}2.63 \\
(0.11)\end{array}$ & & $\begin{array}{l}2.66 \\
(0.12)\end{array}$ \\
\hline Dummy - US & & $\begin{array}{l}0.41 \\
(0.05) \\
\end{array}$ & $\begin{array}{r}0.40 \\
(0.05) \\
\end{array}$ & & $\begin{array}{r}0.49 \\
(0.06) \\
\end{array}$ & $\begin{array}{l}0.48 \\
(0.06) \\
\end{array}$ \\
\hline Border - Canada & $\begin{array}{l}16.4 \\
(2.0)\end{array}$ & & $\begin{array}{l}15.7 \\
(1.9)\end{array}$ & $\begin{array}{l}13.8 \\
(1.6)\end{array}$ & & $\begin{array}{l}14.2 \\
(1.6)\end{array}$ \\
\hline Border - US & & $\begin{array}{l}1.50 \\
(0.08)\end{array}$ & $\begin{array}{l}1.49 \\
(0.08)\end{array}$ & & $\begin{array}{l}1.63 \\
(0.09)\end{array}$ & $\begin{array}{l}1.62 \\
(0.09)\end{array}$ \\
\hline $\bar{R}^{2}$ & 0.76 & 0.85 & 0.85 & 0.53 & 0.47 & 0.55 \\
\hline \multicolumn{7}{|c|}{ Remoteness Variables Added } \\
\hline Border - Canada & $\begin{array}{l}16.3 \\
(2.0)\end{array}$ & & $\begin{array}{l}15.6 \\
(1.9)\end{array}$ & $\begin{array}{l}14.7 \\
(1.7)\end{array}$ & & $\begin{array}{l}15.0 \\
(1.8)\end{array}$ \\
\hline Border - US & & $\begin{array}{l}1.38 \\
(0.07)\end{array}$ & $\begin{array}{l}1.38 \\
(0.07)\end{array}$ & & $\begin{array}{l}1.42 \\
(0.08)\end{array}$ & $\begin{array}{l}1.42 \\
(0.08)\end{array}$ \\
\hline $\bar{R}^{2}$ & 0.77 & 0.86 & 0.86 & 0.55 & 0.50 & 0.57 \\
\hline
\end{tabular}

Table 1: McCallum regressions

Notes : The table reports the results of estimating a McCallum-gravity equation for the year 1993 for 30 U.S. states and 10 Canadian provinces. In all regressions the dependent variable is the $\log$ of exports from region $i$ to region $j$. The independent variables are defined as follows: $y_{i}$ and $y_{j}$ are gross domestic production in regions $i$ and $j ; d_{i j}$ is the distance between regions $i$ and $j$; Dummy-Canada and Dummy-US are dummy variables that are 1 when both regions are located in respectively Canada and the United States, and zero otherwise. The first three columns report results based on non-unitary income elasticities (as in the original McCallum regressions), while the last 3 columns assume unitary income elasticities. Results are reported for three different sets of data: state-province and interprovincial trade, (ii) state-province and interstate trade, (iii) state-province, interprovincial and interstate trade. The border coefficients Border-US and Border-Canada are the exponentials of the coefficients on the respective dummy variables. The final three rows report the border coefficients and $\bar{R}^{2}$ when the remoteness indices (3) are added. Robust standard errors are in parentheses. 


\begin{tabular}{|c|c|c|c|}
\hline & & $\begin{array}{l}\text { Two-Country } \\
\text { Model }\end{array}$ & $\begin{array}{l}\text { Multi-Country } \\
\text { Model }\end{array}$ \\
\hline \multirow[t]{5}{*}{ Parameters: } & $(1-\sigma) \rho$ & $\begin{array}{l}-0.79 \\
(0.03)\end{array}$ & $\begin{array}{l}-0.82 \\
(0.03)\end{array}$ \\
\hline & $(1-\sigma) \ln b_{U S, C A}$ & $\begin{array}{l}-1.65 \\
(0.08)\end{array}$ & $\begin{array}{l}-1.59 \\
(0.08)\end{array}$ \\
\hline & $(1-\sigma) \ln b_{U S, R O W}$ & & $\begin{array}{l}-1.68 \\
(0.07)\end{array}$ \\
\hline & $(1-\sigma) \ln b_{C A, R O W}$ & & $\begin{array}{l}-2.31 \\
(0.08)\end{array}$ \\
\hline & $(1-\sigma) \ln b_{R O W, R O W}$ & & $\begin{array}{l}-1.66 \\
(0.06)\end{array}$ \\
\hline \multirow{3}{*}{$\begin{array}{l}\text { Average Error } \\
\text { Terms: }\end{array}$} & US-US & 0.06 & 0.06 \\
\hline & $\mathrm{CA}-\mathrm{CA}$ & -0.17 & -0.02 \\
\hline & US-CA & -0.05 & -0.04 \\
\hline
\end{tabular}

Table 2: Estimation Results

Notes: The table reports parameter estimates from the two-country model and the multi-country model. Robust standard errors are in parentheses. The table also reports average error terms for interstate, interprovincial and state-province trade.

\begin{tabular}{||lccc||}
\hline \hline & US & Canada & ROW \\
\hline & \multicolumn{4}{c||}{ Two-Country Model } \\
\hline With Border Barrier & 0.77 & 2.45 & \\
(BB) & $(0.03)$ & $(0.12)$ & \\
Borderless Trade & 0.75 & 1.18 & \\
(NB) & $(0.03)$ & $(0.01)$ & \\
Ratio (BB/NB) & 1.02 & 2.08 & \\
& $(0.00)$ & $(0.08)$ & \\
\hline & Multi-Country & Model \\
\hline With Border Barrier & 1.55 & 4.67 & 2.97 \\
(BB) & $(0.01)$ & $(0.09)$ & $(0.07)$ \\
Borderless Trade & 1.39 & 1.91 & 1.54 \\
(NB) & $(0.00)$ & $(0.04)$ & $(0.01)$ \\
Ratio (BB/NB) & 1.12 & 2.44 & 1.93 \\
& $(0.01)$ & $(0.09)$ & $(0.06)$ \\
\hline \hline
\end{tabular}

Table 3: Multilateral Resistance Variables

Notes : The table reports the average of $P_{i}^{\sigma-1}$, where the average is defined as the exponential of the average logarithm. For the US the average is taken over the 30 states in the sample, for Canada over the 10 provinces and for ROW over the other 20 industrialized countries. 


\begin{tabular}{|c|c|c|c|c|c|c|}
\hline & US-US & CA-CA & US-CA & US-ROW & CA-ROW & ROW-ROW \\
\hline & \multicolumn{6}{|c|}{ Two-Country Model } \\
\hline Ratio BB/NB & $\begin{array}{l}1.05 \\
(0.01)\end{array}$ & $\begin{array}{l}4.31 \\
(0.34)\end{array}$ & $\begin{array}{l}0.41 \\
(0.02)\end{array}$ & & & \\
\hline $\begin{array}{l}\text { Due to bilateral } \\
\text { resistance }\end{array}$ & $\begin{array}{l}1.0 \\
(0.0)\end{array}$ & $\begin{array}{l}1.0 \\
(0.0)\end{array}$ & $\begin{array}{l}0.19 \\
(0.01)\end{array}$ & & & \\
\hline \multirow[t]{2}{*}{$\begin{array}{l}\text { Due to multilateral } \\
\text { resistance }\end{array}$} & $\begin{array}{l}1.05 \\
(0.01)\end{array}$ & $\begin{array}{l}4.31 \\
(0.34)\end{array}$ & $\begin{array}{l}2.13 \\
(0.09)\end{array}$ & & & \\
\hline & \multicolumn{6}{|c|}{ Multi-Country Model } \\
\hline Ratio BB/NB & $\begin{array}{l}1.25 \\
(0.02)\end{array}$ & $\begin{array}{l}5.96 \\
(0.42)\end{array}$ & $\begin{array}{l}0.56 \\
(0.03)\end{array}$ & $\begin{array}{l}0.40 \\
(0.01)\end{array}$ & $\begin{array}{l}0.46 \\
(0.01)\end{array}$ & $\begin{array}{l}0.71 \\
(0.02)\end{array}$ \\
\hline $\begin{array}{l}\text { Due to bilateral } \\
\text { resistance }\end{array}$ & $\begin{array}{l}1.0 \\
(0.0)\end{array}$ & $\begin{array}{l}1.0 \\
(0.0)\end{array}$ & $\begin{array}{l}0.20 \\
(0.02)\end{array}$ & $\begin{array}{l}0.19 \\
(0.01)\end{array}$ & $\begin{array}{l}0.10 \\
(0.01)\end{array}$ & $\begin{array}{l}0.19 \\
(0.01)\end{array}$ \\
\hline $\begin{array}{l}\text { Due to multilateral } \\
\text { resistance }\end{array}$ & $\begin{array}{l}1.25 \\
(0.02)\end{array}$ & $\begin{array}{c}5.96 \\
(0.42)\end{array}$ & $\begin{array}{l}2.72 \\
(0.12)\end{array}$ & $\begin{array}{l}2.15 \\
(0.09)\end{array}$ & $\begin{array}{l}4.70 \\
(0.31)\end{array}$ & $\begin{array}{l}3.71 \\
(0.25)\end{array}$ \\
\hline
\end{tabular}

Table 4: Impact of Border Barriers on Bilateral Trade

Notes : The table reports the ratio of trade with the estimated border barriers (BB) to that under borderless trade (NB). This ratio is broken down into the impact of border barriers on trade through bilateral resistance $\left(t_{i j}^{1-\sigma}\right)$ and through multilateral resistance $\left(P_{i}^{\sigma-1} P_{j}^{\sigma-1}\right)$.

\begin{tabular}{||lcc|cc||}
\hline \hline & \multicolumn{2}{c|}{ Two-Country Model } & \multicolumn{2}{|c||}{ Multi-Country Model } \\
\hline & Canada & US & Canada & US \\
\hline theoretically consistent & 10.5 & 2.56 & 10.7 & 2.24 \\
estimate & $(1.16)$ & $(0.13)$ & $(1.06)$ & $(0.12)$ \\
McCallum parameter & 16.5 & 1.64 & 14.8 & 1.63 \\
implied by theory & $(1.63)$ & $(0.09)$ & $(1.32)$ & $(0.10)$ \\
\hline \hline
\end{tabular}

Table 5: Impact Border on Intranational Trade Relative to International Trade

Notes : The first row of the table reports the theoretically consistent estimate of the impact of border barriers on intranational trade relative to international trade, for both Canada and the United States. The second row reports the McCallum border parameter implied by the model, which provides a biased estimate of the impact of borders on the ratio of intranational to international trade. 


\begin{tabular}{|c|c|c|c|c|c|c|c|c|}
\hline & (i) & (ii) & (iii) & (iv) & $(\mathrm{v})$ & (vi) & (vii) & (viii) \\
\hline & \multicolumn{8}{|c|}{ Two-Country Model } \\
\hline \multicolumn{9}{|l|}{ Trade (BB/NB) } \\
\hline US-US & $\begin{array}{c}1.05 \\
(0.01)\end{array}$ & $\begin{array}{c}1.05 \\
(0.01)\end{array}$ & $\begin{array}{c}1.05 \\
(0.01)\end{array}$ & $\begin{array}{l}1.05 \\
(0.01)\end{array}$ & $\begin{array}{c}1.04 \\
(0.01)\end{array}$ & $\begin{array}{c}1.04 \\
(0.00)\end{array}$ & $\begin{array}{c}1.03 \\
(0.00)\end{array}$ & \\
\hline $\mathrm{CA}-\mathrm{CA}$ & $\begin{array}{c}4.31 \\
(0.34)\end{array}$ & $\begin{array}{c}4.26 \\
(0.34)\end{array}$ & $\begin{array}{c}4.31 \\
(0.30)\end{array}$ & $\begin{array}{c}4.41 \\
(0.39)\end{array}$ & $\begin{array}{c}3.92 \\
(0.53)\end{array}$ & $\begin{array}{c}3.82 \\
(0.29)\end{array}$ & $\begin{array}{c}4.37 \\
(0.38)\end{array}$ & \\
\hline US-CA & $\begin{array}{c}0.41 \\
(0.02)\end{array}$ & $\begin{array}{c}0.41 \\
(0.02)\end{array}$ & $\begin{array}{c}0.41 \\
(0.02)\end{array}$ & $\begin{array}{c}0.41 \\
(0.02)\end{array}$ & $\begin{array}{c}0.50 \\
(0.03)\end{array}$ & $\begin{array}{c}0.50 \\
(0.02)\end{array}$ & $\begin{array}{c}0.54 \\
(0.02)\end{array}$ & \\
\hline \multicolumn{9}{|c|}{ McCallum parameter } \\
\hline US & $\begin{array}{c}1.64 \\
(0.09)\end{array}$ & $\begin{array}{c}1.64 \\
(0.09)\end{array}$ & $\begin{array}{c}1.58 \\
(0.08)\end{array}$ & $\begin{array}{c}1.70 \\
(0.09)\end{array}$ & $\begin{array}{l}1.37 \\
(0.11)\end{array}$ & $\begin{array}{c}1.03 \\
(0.05)\end{array}$ & $\begin{array}{c}1.05 \\
(0.06)\end{array}$ & \\
\hline $\mathrm{CA}$ & $\begin{array}{c}16.5 \\
(1.63)\end{array}$ & $\begin{array}{c}16.5 \\
(1.63)\end{array}$ & $\begin{array}{c}17.1 \\
(1.64)\end{array}$ & $\begin{array}{c}16.1 \\
(1.65)\end{array}$ & $\begin{array}{c}12.2 \\
(1.93)\end{array}$ & $\begin{array}{c}15.4 \\
(1.50)\end{array}$ & $\begin{array}{c}14.9 \\
(1.63)\end{array}$ & \\
\hline & \multicolumn{8}{|c|}{ Multi-Country Model } \\
\hline \multicolumn{9}{|l|}{ Trade (BB/NB) } \\
\hline US-US & $\begin{array}{c}1.25 \\
(0.02)\end{array}$ & $\begin{array}{c}1.26 \\
(0.02)\end{array}$ & $\begin{array}{l}1.21 \\
(0.02)\end{array}$ & $\begin{array}{c}1.29 \\
(0.02)\end{array}$ & $\begin{array}{l}1.22 \\
(0.04)\end{array}$ & $\begin{array}{c}1.19 \\
(0.02)\end{array}$ & $\begin{array}{c}1.18 \\
(0.02)\end{array}$ & $\left(\begin{array}{l}1.14 \\
0.02)\end{array}\right.$ \\
\hline $\mathrm{CA}-\mathrm{CA}$ & $\begin{array}{c}5.96 \\
(0.42)\end{array}$ & $\begin{array}{c}5.93 \\
(0.42)\end{array}$ & $\begin{array}{l}5.90 \\
(0.37)\end{array}$ & $\begin{array}{c}6.21 \\
(0.49)\end{array}$ & $\begin{array}{c}5.07 \\
(0.66)\end{array}$ & $\begin{array}{c}5.03 \\
(0.36)\end{array}$ & $\begin{array}{c}5.21 \\
(0.40)\end{array}$ & $\begin{array}{c}4.44 \\
(0.39)\end{array}$ \\
\hline US-CA & $\begin{array}{c}0.56 \\
(0.03)\end{array}$ & $\begin{array}{c}0.56 \\
(0.03)\end{array}$ & $\begin{array}{c}0.54 \\
(0.03)\end{array}$ & $\begin{array}{c}0.57 \\
(0.03)\end{array}$ & $\begin{array}{c}0.63 \\
(0.05)\end{array}$ & $\begin{array}{c}0.62 \\
(0.03)\end{array}$ & $\begin{array}{c}0.63 \\
(0.03)\end{array}$ & $\begin{array}{c}0.51 \\
(0.03)\end{array}$ \\
\hline ROW-ROW & $\begin{array}{c}0.71 \\
(0.02)\end{array}$ & $\begin{array}{c}0.70 \\
(0.02)\end{array}$ & $\begin{array}{c}0.71 \\
(0.02)\end{array}$ & $\begin{array}{c}0.72 \\
(0.02)\end{array}$ & $\begin{array}{c}0.83 \\
(0.06)\end{array}$ & $\begin{array}{c}0.50 \\
(0.02)\end{array}$ & $\begin{array}{c}0.87 \\
(0.04)\end{array}$ & $\begin{array}{c}0.76 \\
(0.04)\end{array}$ \\
\hline \multicolumn{9}{|c|}{ McCallum parameter } \\
\hline US & $\begin{array}{c}1.63 \\
(0.10)\end{array}$ & $\begin{array}{c}1.63 \\
(0.10)\end{array}$ & $\begin{array}{l}1.56 \\
(0.09)\end{array}$ & $\begin{array}{c}1.69 \\
(0.11)\end{array}$ & $\begin{array}{c}1.38 \\
(0.12)\end{array}$ & $\begin{array}{c}1.13 \\
(0.06)\end{array}$ & $\begin{array}{c}1.19 \\
(0.08)\end{array}$ & $\begin{array}{c}1.56 \\
(0.09)\end{array}$ \\
\hline $\mathrm{CA}$ & $\begin{array}{c}14.8 \\
(1.32)\end{array}$ & $\begin{array}{c}14.8 \\
(1.32)\end{array}$ & $\begin{array}{c}15.3 \\
(1.34)\end{array}$ & $\begin{array}{c}14.5 \\
(1.33)\end{array}$ & $\begin{array}{c}11.1 \\
(1.57)\end{array}$ & $\begin{array}{c}13.6 \\
(1.37)\end{array}$ & $\begin{array}{c}12.9 \\
(1.29)\end{array}$ & $\begin{array}{c}12.4 \\
(1.25)\end{array}$ \\
\hline
\end{tabular}

\section{Table 6: Sensitivity Analysis}

Notes: The table reports sensitivity analysis with regards to the ratio of trade with border barriers to trade without border barriers and with regards to the McCallum border parameters implied by the model. Column (i) repeats results from the benchmark regression. Column (ii) assumes $\sigma=10$ (in the benchmark $\sigma=5$ ). Columns (iii) and (iv) report results when respectively doubling and halving distances internal to regions and countries. Column (v) reports results based on a regression that does not use interstate data. Columns (vi) and (vii) report results when income $y$ is replaced by $x^{\alpha} y$ with $x$ respectively income $y$ and per capita income $y / N . x^{\alpha}$ represents the fraction spent on tradables in a region or country. The final column reports for the multi-country case results when minimizing the sum of all squared error terms, including those involving ROW countries. 